
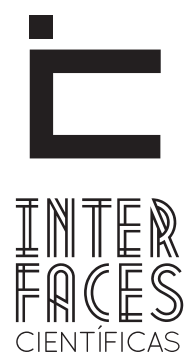

EDUCAÇ̃̃o

ISSN IMPRESSO 2316-333X

ISSN ELETRÔNICO 2316-3828

Dossiê

\title{
A EDUCAÇ̃̃O DA INFÂNCIA RETRATADA ATRAVÉS DA LITERATURA
}

Solyane Silveira Lima ${ }^{1}$

\section{RESUMO}

Este artigo apresenta como objeto de investigação a educação da infância vivenciada no final do século XIX, presente em duas obras autobiográficas, quais sejam: Minha vida de menina escrita por Helena Morley e História da minha infância, de Gilberto Amado. 0 objetivo é discutir o uso da literatura como fonte para os estudos históricos, neste caso especificamente, na História da Educação da Infância. Para tanto, organizaremos o texto em três momentos. Inicialmente discutiremos a infância e sua educação a partir dos pressupostos lançados
Anne Emilie Souza de Almeida Cabral ${ }^{2}$

pela História Cultural. Em seguida, como essa abordagem historiográfica possibilitou a abertura do campo para a utilização de novas fontes e objetos, dentre os quais se encontra a Literatura. E, por fim, analisaremos as obras literárias com o intuito de demonstrar como é possível operacionalizar questões referentes à temática enunciada.

\section{PALAVRAS-CHAVE}

Infância. História. Educação. Literatura. 


\section{ABSTRACT}

This article presents the education of children lived in the late nineteenth century, present in two autobiographical works, which are the object of research: Minha vida de menina written by Helena Morley and História da minha infância, Gilberto Amado. The objective is to discuss the use of literature as the source for historical studies, in this case specifically, in the History of Childhood Education. To do so, we will organize the text into three parts. Initially discuss childhood and his education from the assumptions launched by
Cultural History. Then, as this historiographical approach permitted the opening of the field for the use of new sources and objects, among whom is the Literature. Finally, we will analyze literary works with the intention of demonstrate how to it is possible to operationalize questions related to the thematic enunciated.

\section{KEYWORDS}

Childhood. History. Education. Literature.

\section{RESUMEN}

En este artículo se presenta la educación de los niños vivía a finales del siglo XIX, presente en dos obras autobiográficas, que son el objeto de la investigación : Minha vida de menina escrito por Helena Morley e História da minha infância, Gilberto Amado. El objetivo es discutir el uso de la literatura como fuente para los estudios históricos, en este caso concreto, en la Historia de la Educación Infantil. Por tanto, vamos a organizar el texto en tres partes. Inicialmente vamos a discutir la infancia y su educación de las hipótesis lanzadas por la His- toria Cultural. Entonces, como este enfoque historiográfico permite la apertura del campo para el uso de nuevas fuentes y objetos, entre los cuales es la literatura. Por último, vamos a analizar las obras literarias con el fin de demostrar cómo es posible poner en práctica las cuestiones relacionadas con el tema enunciado.

\section{PALABRAS CLAVE}

Infancia. Historia. Educación. Literatura. 


\section{INTRODUCÇÃO}

O objetivo principal deste artigo é discutir o uso da literatura como fonte para os estudos em história da educação da infância. A análise será construída a partir de duas obras autobiográficas, que revelam aspectos educacionais vivenciados pelos autores, quando crianças, no final do século XIX.

Para empreender essa tarefa, partimos do pressuposto que o texto literário pode ser utilizado tanto como fonte quanto como objeto de estudo. Como fonte quando empregamos as obras para explicar um fato e como objeto quando as analisamos. Porém, essa maneira de pensar e agir só se tornou possível após a abertura do campo de pesquisa, influenciada pelo discurso da História Cultural.

A História Cultural pode ser definida como uma tendência historiográfica que propõe uma forma inovadora de interrogar a realidade e "tem como principal objetivo identificar o modo como em diferentes lugares e momentos uma determinada realidade social é construída, pensada, dada a ler". (FERRO, 2000, p. 09).

[...] a história cultural afasta-se sem dúvida de uma dependência demasiado estrita em relação a uma história social fadada apenas ao estudo das lutas econômicas, mas também faz retorno útil sobre o social, já que dedica atenção às relações e que constroem, para cada classe, grupo ou meio, um "ser-percebido" constitutivo de sua identidade. (CHARTIER, 2002, p. 23).

Essa postura que se convencionou chamar de Historia Cultural proporcionou a partir dos seus pressupostos e preocupações uma abertura dos campos da pesquisa para a utilização de novas fontes e objetos na pesquisa histórica. E, apesar do leque de possibilidades que ela oferece, não podemos perder de vista a criticidade diante de cada fonte, pois:

[...] nenhum documento é inocente. Deve ser analisado. Todo documento é um monumento que deve se desestruturado, desmontado. 0 historiador não deve ser apenas capaz de discernir o que é "falso", avaliar a credibilidade do documento, mas também, saber desmistificá-lo. Os documentos só passam a ser fontes históricas depois de estar sujeitos a tratamentos destinados a transformar sua função de mentira em confissão de verdade. (LE GOFF, 2003, p. 110).

Nesse sentido é necessário que o investigador da História Cultural seja capaz de identificar todas as fontes possíveis, criticá-las e estabelecer diálogo entre fontes e teoria. Dessa maneira a História Cultural ganhou espaço no meio acadêmico e também na História da Educação, proporcionando seu crescimento epistemológico à medida que propunha novos objetos e novas interpretações ampliando o campo de investigação.

No bojo dessa abordagem histórica é que se faz possível a discussão de temas e objetos que passavam despercebidos ou que eram desprezados pela história. Dentre estes, podemos destacar os estudos sobre a infância e o uso da literatura como fonte para a História da Educação.

\section{INFÂNCIA E SUA EDUCAÇÃO SOB A ÓTICA DA HISTÓRIA CULTURAL}

De acordo com o dicionário da língua portuguesa Houaiss, a palavra Infância significa o período da vida humana que vai do nascimento ao início da adolescência. Para a etimologia, esta palavra oriunda do latim e significa a incapacidade de falar. Essa incapacidade é atribuída, em geral, ao período que chamamos de primeira infância, o qual se estende até os seis anos.

As discussões e produções sobre essa temática tem sido crescentes no campo acadêmico, porém ainda percebemos a dificuldade que a sociedade apresenta em lidar com as crianças. Mesmo em face dos diálogos e das lutas em defesa dos direitos da criança, muitos adultos insistem em considerar essa etapa da vida humana como um período de incapacidade e quase sempre "a criança é tomada como objeto dos pais e, não raro, como bibelô da família”. (DAMÁZIO, 1995, p. 29). 
A história cultural colaborou com esse tema a partir do momento que houve uma mudança de interesses de alguns historiadores dos Annales ${ }^{3}$. A história das mentalidades deixou de ocupar a margem dos projetos dos Annales e foi levada para o centro da discussão através do historiador francês Philippe Ariès e de sua obra, História social da criança e da família, publicada em 1960.

Foi realmente um historiador da geração de Braudel que despertou a atenção pública para a história das mentalidades através de um livro notável, quase sensacional, publicado em 1960.

[...] Demógrafo histórico por formação, Ariès veio rejeitar a perspectiva quantitativa (da mesma maneira que rejeitou outros aspectos do mundo burocrático-industrial moderno). Seus interesses direcionaram-se para a relação entre natureza e cultura, para as formas pelas quais uma cultura vê e classifica fenômenos naturais, tais como a infância e a morte. (BURKE, 1991, p. 81).

Nesse estudo Ariès (1978) propõe o enfoque nos comportamentos e identifica a ausência de um sentimento de infância até o final do século XVIII. Segundo ele, na Idade Média a arte não retratou a criança, demonstrando com isso que, naquele tempo, não existia um sentimento de infância como uma fase separada da existência humana, com características especiais. A concepção que predominava era a de um adulto em miniatura.

A partir do século XV observa-se uma nova concepção de infância, um distanciamento entre o mundo adulto e o universo infantil. A criança nobre torna-se fonte de alegria dos adultos, surge 0 sentimento de dor e piedade pelas crianças que morriam, conservando-se os retratos dos filhos falecidos e vivos. A aproximação entre os pais e as crianças gerou o sentimento de família e infância que antes não existia.

3. A Escola dos Annales surge em 1929 com Marc Bloch e Lucien Febvre, como um movimento que se contrapunha ao paradigma da historiografia tradicional. Segundo Peter Burke, "Essa Escola é, amiúde, vista como um grupo monolítico, com uma prática histórica uniforme, quantitativa no que concerne ao método determinista em suas concepções, hostil ou, pelo menos, indiferente à politica e aos eventos". (1991, p. 12).
Assim que a criança deixava os cueiros, ou seja, a faixa de tecido que era enrolada em torno de seu corpo, ela era vestida como os outros homens e mulheres de sua condição [...]. A Idade Média vestia indiferentemente todas as classes de idade, preocupando-se apenas em manter visíveis através da roupa os degraus da hierarquia social. Nada no traje medieval, superava a criança do adulto. Não seria possível imaginar atitudes mais diferentes com relação à infância.

No século XVII, entretanto a criança, ou ao menos a criança de boa família, quer fosse nobre ou burguesa, não era mais vestida como os adultos. Ela agora tinha um traje reservado à sua idade, que a distinguia dos adultos. (ARIĖS, 1978, p. 32).

O sentimento moderno de infância, segundo esse autor, correspondia a duas atitudes antagônicas dos adultos: a primeira que considerava a criança ingênua, inocente e pura, que é traduzido pelo que ele denominou de "paparicação", a segunda, a exasperação, se contrapõe àquela e toma a criança como um ser imperfeito e incompleto que precisa de moralização e da educação dada pelo adulto.

A obra de Philippe Ariès foi um divisor na historiografia mundial, apesar de ter gerado muitas polêmicas e muitas críticas por parte dos historiadores. Ele se utilizou de uma grande variedade de fontes, tais como a literatura e a arte. Consoante Burke, seu grande feito está no fato de ter posto a criança dentro da discussão histórica. "Pelo sim, pelo não, foi uma contribuição de Ariès colocar a infância no mapa histórico, inspirar centenas de estudos sobre a história da criança em diferentes regiões e períodos, e chamar a atenção de psicólogos e pediatras para a nova história”. (BURKE, 1991, p. 82).

Outro importante autor que trabalha a partir das vertentes da história cultural no campo da história da infância, porém para o caso brasileiro, é o pesquisador Moysés Kuhlmann Júnior. Segundo ele a educação infantil é ainda muito desvalorizada nas pesquisas educacionais e principalmente a sua história. 
Ele aponta como motivo principal o fato de que as instituições educacionais voltadas para atendimento a infância não tiveram, no decorrer da história, um caráter de obrigatoriedade, como a escola primária. Além de suas origens estarem ligadas a caridade, a filantropia e a solidariedade religiosa.

Na obra, Infância e educação infantil: uma abordagem histórica (1998), Kuhlmann Jr. Enfoca a questão da importância da história no campo da pesquisa sobre a infância e sua educação, tratando de várias questões que envolvem a história das instituições de educação infantil e suas relações com a história da proteção e da assistência à criança. Bem como, as políticas e algumas concepções pedagógicas que fundamentaram as propostas e práticas da educação da criança de zero a seis anos de idade.

Assim, embora dedicando-se privilegiadamente ao período de transição do século XIX ao XX, o conjunto de temas tratados permite uma compreensão mais aprofundada das questões que envolvem o estudo histórico da educação infantil. Em boa parte deles, além das análises do tema específico, defende-se a interpretação de que tanto creches, como jardins-de-infância e escolas maternais, constituíram-se como instituições educacionais. (KUHLMANN JR., 1998, p. 01).

O autor considera a história da educação como parte integrante da produção da história e não como elemento isolado. Pois que a educação não é um fenômeno que acontece e permanece no interior do âmbito educacional. A ideia é encontra-la no estudo das relações sociais, no estudo da história, ao invés de considerar as reformas legislativas ou o Estado e as suas instâncias administrativas.

Portanto, diante da exposição apresentada sobre essas duas obras publicadas no âmbito da história cultural, é inegável a influência desta vertente nos estudos sobre a infância e a sua educação. Fato que possibilitou novos olhares e novas possibilidades para as pesquisas nesse campo.

\section{A LITERATURA COMO FONTE PARA HISTÓRIA DA INFÂNCIA}

Conforme exposto anteriormente a História Cultural trouxe para o campo da pesquisa histórica novas possibilidades de manuseio de fontes até então desprestigiadas. Partindo dessa nova perspectiva foi que se compreendeu a validade de diversos tipos de fonte, dentre elas a literatura.

O diálogo da história com a literatura tem se revelado uma das temáticas mais promissoras em termos de pesquisa e trabalhos publicados. A literatura “... categoria que, a partir do século XVIII, rotula um tipo especial de leitura e de escrita, que é simultaneamente, matéria-prima e produto de práticas muito determinadas" (LAJOLO e ZILBERMAN, 1998, p. 308), pode ser utilizada tanto como fonte para estudo como campo de manifestação.

De acordo com Maria Cristina Soares de Gouvêa (2007) a História Cultural ao tomar como objeto a literatura, produziu estratégias metodológicas voltadas para a análise dos mecanismos de produção, circulação e recepção do escrito, expressos nas representações presentes na obra, sua materialidade, domínio de sua significação e das práticas sociais de apropriação. Essa perspectiva significa não apenas o alargamento do campo de análise, mas também a contemplação de mecanismos e estratégias próprias de expressão das práticas culturais.

Nessa direção, a autora afirma que analisar as representações significa atentar-se para dispositivos textuais que dão sentido a realidade construída e expressa na obra literária, buscando compreender o universo sociocultural retratado pelo autor. E para além das representações expressas nas obras, o estudo da materialidade do objeto livro significa analisar os dispositivos tipográficos, a relação com a imagem, as mudanças históricas nas edições, aspectos que conferem as obras sua condição de leitura. 
Assim, a tradição da História Cultural ao trabalhar com a literatura, voltou-se preponderantemente para a produção de uma história da leitura, entendida, em termos gerais, como "produção de sentido a partir da experiência do leitor” (CHARTIER, 2001, p. 95). Dessa maneira busca-se analisar como o texto literário foi apropriado por meio de práticas de leitura socialmente definidas, trazendo para a discussão o estudo dos mecanismos de circulação das obras e sua recepção, numa perspectiva sustentada no diálogo com o leitor, mediada pelo escrito.

Destarte observamos que a literatura é uma importante fonte para o historiador, pois permite enxergar traços e pistas que outras fontes, talvez, não lhes proporcionassem. A literatura é uma narrativa que, seja pela poesia ou pela prosa, fala ao mundo de forma indireta e metafórica. E por vezes, o sentido que o texto literário apresenta é o suporte necessário para que o olhar do historiador se oriente para outras fontes e nelas consiga enxergar o que ainda não viu, cumprindo assim um efeito multiplicador de possibilidades de leitura, conforme observaremos no próximo item.

\section{OBRAS AUTOBIOGRÁFICAS: LITERATURA E INFÂNCIA EM QUESTÃO}

Para elucidar o modo pelo qual a literatura pode ser utilizada no estudo da história da infância vamos apresentar dois livros que tratam desse tema no final do século XIX. Ambos são obras autobiográficas que retratam a infância vivida no interior do Brasil.

O primeiro é o diário de Alice Dayrell Caldeira Brant, que escreve sob o pseudônimo de Helena Morley. A história foi escrita em Diamantina - MG entre os anos 1893 a 1895. O segundo livro, escrito por Gilberto Amado, retrata as memórias de sua infância no interior de Sergipe, nas vilas de Estância e Itaporanga, na última década do século XIX.

\section{Minha Vida de Menina - Helena Morley}

Publicado no Brasil em 1942, "Minha Vida de Menina" é o diário de uma adolescente de origem inglesa de treze anos, que afirma que a escrita da obra aconteceu de maneira incidental, por influência paterna e exigência do seu professor de português.

As histórias do livro são descritas com leveza. Nele estão retratados aspectos da vida da cidade, descrições de parentes e amigos, da vida no garimpo, as histórias de família e as reflexões cheias de graça e originalidade da narradora ainda menina.

\begin{abstract}
Se me dessem a Diamantina para dirigir, a última coisa que eu poria aqui seria repartição de correio. Não posso compreender como um serviço que Seu Cláudio, aleijado, que precisava ser carregado por um preto e posto em cima do cavalo, fazia tão bem, levando na garupa o saco com as cartas e jornais, precisa agora de uma repartição tão aparatosa, com tanto homem dentro. Meu pai diz que tudo isso é política, só para dar empregos. Mas não seria melhor que em vez de administração de correios eles pusessem luz nas ruas para a gente, nas noites escuras, não estar andando devagar com medo de cair em cima de uma vaca? E encanar a água? Isso também não seria mais útil? Sem carta ninguém morre, mas a água do pau de Fruta, que corre descoberta, tem matado tanta gente que podia estar viva. Diz que a febre tifo vem da água. Tudo isso melhoraria muito mais a cidade do que repartições de correios. (MORLEY, 1998, p. 235).
\end{abstract}

A economia decadente da velha Diamantina refletia, nestes primeiros anos da república, um país agrário, conservador, atrasado e racista. A escravidão acabara de ser abolida, mas os negros continuavam na base da escala social. Pobreza, racismo e autoritarismo permeavam a rotina diária. A igreja católica dominava as mentes e corações, chegando ao ponto de recusar o sepultamento do avô paterno de Helena porque ele era inglês e protestante.

Os aspectos relacionados à educação também são expostos pela autora, porém de uma maneira fluída em alguns capítulos. Em um deles ela demonstra sua opinião sobre a escola, e assim escreve:

Faz hoje três dias que eu entrei para a Escola Normal. Comprei meus livros e vou começar vida nova. 0 pro- 
fessor de português aconselhou todas as meninas a irem se acostumando a escrever, todo dia, uma carta ou qualquer coisa que thes acontecer.

[...]

Tia Madge disse que Mestra Joaquininha lhe falou que eu fui a aluna mais inteligente da escola dela, mas era vadia e falhava dias seguidos. Isso é verdade, porque ano passado fomos, muitas vezes, passar dias com meu pai na Boa vista. [...]. Hoje (na escola) já vi o jeito. Achei tudo difícil e complicado. 0 que me vale é que tenho facilidade de decorar. Quando eu não puder compreender, decoro tudo. Mas no Português como é que vou decorar? Análise, eu nem sei onde se pode estudar. Só daqui a dias poderei saber como as coisas vão sair. Escrever não vai ser difícil, pelo costume em que meu pai me pôs de escrever quase todo dia. Duas coisas eu gosto de fazer, escrever e ler histórias, quando encontro. (MORLEY, 1998, p. 26).

Outro momento que ela relata seu ponto de vista é quando nos fala sobre a volta as aulas.

A escola abriu ontem e as aulas vão começar segunda-feira. Recebemos a lista dos livros, mas ainda não deram os horários. Todos animados.

[...]

Por felicidade nossa foi adotado uniforme para nós na escola. É de uma fazenda forte, azul-escuro, que suja pouco e é muito durável. Mamãe vai descansar da luta de me arranjar vestidos para a escola, que the estava dando um trabalho horrível. Com o uniforme agora tudo será mais fácil; eu mesma o lavarei na quarta-feira e passarei na quinta. Queria só saber da cabeça de quem saiu esta ideia tão boa, que devia ter aparecido há mais tempo. (MORLEY, 1998, p. 129)

Nesta obra também encontramos indícios de uma educação que acontecia no lar, concomitante a educação escolar. Inicialmente quando a autora diz que seu pai lhe acostumou a escrever quase todos os dias e também quando afirma que suas tias pediam que ela lesse em voz alta histórias em inglês.

Eu fui acabando de aprender a ler e tia Madge, que só acha bom o que é inglês, arranjou O Poder da Vontade e me fez ler para ela ouvir. Acabado este deu-me outro: O Caráter. Eu tinha de ler e contar-lhe tudo tintim por tintim. Afinal os dois dão na mesma coisa: economia, correção, força de vontade. (MORLEY, 1998, p. 58).
Dentro da sua despretensão, como nos afirma a autora, Minha Vida de Menina é um livro importante para a compreensão de aspectos da sociedade brasileira, já que descreve uma parte central da nossa identidade. Além de que, a partir dessa obra, podemos conhecer alguns detalhes da educação que se ofertava tanto na escola quanto na casa para as crianças e adolescente do final do século XIX.

\section{História da Minha Infância - Gilberto Amado}

Lançado em 1954, o livro escrito por Gilberto Amado ${ }^{4}$ retrata suas memórias de menino sergipano que viveu nas vilas de Estância e Itaporanga na última década do século XIX. Retoma as lembranças de criança, através do relato das brincadeiras infantis, as peripécias de adolescente, descrevendo os seus estudos em Itaporanga e a vida de estudante de Farmácia em Salvador.

Sobre essa questão da educação, encontramos o seu relato a respeito das escolas de primeiras letras, que funcionavam geralmente na própria residência do mestre e em condições precárias, nas quais o professor nomeado pelo governo ou particularmente oferecia instrução às crianças. Em Sergipe não poderia ser diferente, principalmente se tratando de cidades do interior.

\footnotetext{
4. Gilberto de Lima Azevedo Souza Amado de Faria nasceu em Estância (SE) em 1887 e faleceu no Rio de Janeiro (RJ) em 1969. Eleito em 3 de outubro de 1963 para a cadeira $n^{\circ} 26$ da Academia Brasileira de Letras, na sucessão de Ribeiro Couto, foi recebido em 29 de agosto de 1964, por Alceu Amoroso Lima. Era o primeiro dos 14 filhos do casal Melchisedech Amado e Ana Amado. Fez os estudos primários em Itaporanga, também no interior de Sergipe. Depois estudou farmácia na Bahia e diplomou-se pela Faculdade de Direito de Recife, da qual se tornou, ainda muito moço, catedrático de Direito Penal. Transferiu-se para o Rio de Janeiro em 1910, iniciando-se no jornalismo. Sua atividade política começou em 1915, quando se elegeu pela primeira vez deputado federal por Sergipe, permaneceu na Câmara dos Deputados até 1917. Novamente eleito deputado federal em 1921, foi reeleito em 1924, cumprindo mandato até o final de 1926. Ainda em 1927 elegeu-se senador, sempre por seu Estado natal. Sua carreira política terminou com a Revolução de 1930. Serviu como embaixador no Chile, Finlândia, Itália e Suíça. A partir de 1948 foi membro, e muitas vezes presidente, da Comissão de Direito Internacional da Organização das Nações Unidas (ONU). Publicou um grande número de obras, entre memórias, romances, crônicas, estudos filosóficos e políticos-sociológicos.
} 
Na sala atijolada, três bancos encostados às paredes. Bancos altos. Os meninos, em sua maioria, ficavam com as pernas no ar. Depois da minha entrada, puseram mais dois bancos. Na parede do fundo, encostava-se Dona Olímpia, Sá Limpa para toda Itaporanga. (AMADO, 1999, p. 57).

A sala da escola abria para a rua por uma porta sobre dois batentes que davam logo para a lama. (AMADO, 1999, p. 58).

Era um trabalho quando se ia lá fora para não enlamear os pés nos excrementos que, em todas as modalidades e formas que pode assumir, da pirâmide da saúde perfeita até o lagamar da opilação, da disenteria e da ameba, por ali se misturavam. (AMADO, 1999, p. 63).

Nessas instituições encontrava-se frequentemente o uso de castigos, inclusive corporais, por parte dos professores. E o autor não deixou de registrar isso em suas memórias:

... seis bolos estalavam. Oito, nove, dez. às vezes o moleque "soltava-se", o liquido escorria-lhe pelas pernas, mas cadê chorar?!... Depois das palmatoadas, João Alfredo ia para o banco, pegava a tabuada, juntava-se a cantinela: "Quatro veis cinco, vinte; quatro veis seis, vinte e quatro..." Tremia-lhe a voz, mas os olhos fuzilavam triunfo. (AMADO, 1999, p. 59).

[...]

A professora, não discutia a denúncia, impunha 0 castigo. Este consistia, quase sempre, numa tira de papel amarrada na cabeça, como uma coroa, com a palavra Desrespeito, em bastardinho. Alguns meninos se revoltavam, não ofereciam a cabeça para a medida da fita de papel cujos extremos Sá Limpa juntava com goma. Em consequência, levavam meia dúzia de bolos. (AMADO, 1999, p. 61).

Para demonstrar a diferença entre a escola pública e a privada, Gilberto Amado registra a existência da professora Maria Cândida, esta funcionária pública, enquanto que Sá Limpa era professora particular, reafirmando o ideário da época, de que as aulas particulares eram mais eficientes que as públicas. E assim se expressa:

Maria Cândida, solteira, magra, sempre de enxaqueca com rubores súbitos, vivia a passar a mão pela cabeça dolorida. [...]. Solteirona frágil, moça velha de peito murcho nas desesperanças do celibato. Maria Cândida, professora pública, não era ilustrada como Sá
Limpa, professora particular. Sá Limpa "puxava” pelos meninos [...].

Mas se não era ilustrada como Sá Limpa, Maria Cândida organizava mês de Maria como ninguém. (AMADO, 1999, p. 75).

Em outro capítulo encontramos a descrição de sua experiência no colégio interno na capital do Estado, o Colégio Oliveira, que segundo o autor, era o único de Sergipe.

Colégio interno em Aracaju, Colégio Oliveira, único, aliás, do Estado, tinha de internato, no sentido normal do termo, apenas o nome. Era uma casa cheia de muitas janelas, junto do quartel, numa esquina no fim da Rua da Frente, no caminho da Fundição.

[...]

Quando entrei, o colégio estava cheio; quartos atulhados de camas juntas. Os meninos corriam por cima delas sem ter que pular no tijolo... Oliveira ensinava Português, Francês, Geografia, Aritmética e Latim. Latim ninguém estudava, nem livros havia. Eu tomava lições particulares com Alfredo Montes, de Inglês, e com Teixeira de Faria, de Matemáticas. (AMADO, 1999, p. 163).

Deixando o internato, permaneceu um ano sem estudar, voltando depois desse tempo para fazer os exames preparatórios no Ateneu, nos quais foi aprovado. Nesta obra o autor constrói ainda uma análise sobre as escolas brasileiras daquela época, chegando a seguinte conclusão:

[...] escola no Brasil era, no meu tempo arremedo de ensino, a luz da técnica didática. Professores capazes, poucos; a maioria nomeada por política, para emprego no orçamento, não para exercício efetivo do cargo. Em Sergipe criou-se uma cadeira de Grego. Para ela nomearam um farmacêutico de poucas letras mesmo em português... Por que escolheram grego?! Podiam ter criado mais uma cadeira de química, química analítica, industrial, qualquer coisa assim que quadrasse ao menos aparentemente com as habilitações do nomeado. Tal era o descaso por coisas de ensino, e o fim exclusivo dar emprego só pelo emprego, que ninguém censurou, criticou, julgou mal nem o governo, nem o beneficiário. (AMADO, 1999, p. 172).

Gilberto Amado se despede da infância narrando sua experiência na Faculdade de Farmácia da Bahia. 
Na qual via a possibilidade de estudar e de um caminho profícuo para o seu futuro. Apesar da pouca idade (14 anos) foi conhecer a vida de estudante, morando em república.

Lá fui... viver vida de estudante, morar em república, conhecer a boemia e o desadoro daquela existência. (AMADO, 1999, p. 178).

No curso de dois anos de permanência em Salvador sofri em várias repúblicas por ser pequeno, irritadiço de ânimo e tão menor de idade. Encontrei, porem, bons companheiros. (AMADO, 1999, p. 179).

Os dois anos de Bahia foram marcos na minha formação, pelo hábito que durante eles adquiri de estudo regular de matéria definida, de procurar saber de fato e não só para exame. Serviram-me também de encorajamento e de exercício de paciência para coabitar com temperamentos diversos e submeter-me às imposições da convivência com indivíduos indiferentes ou hostis. (AMADO, 1999, p. 185).

Das páginas de História de Minha Infância emanam a ternura, a poesia, o sentimento humano e as lições de vida de uma infância feliz. A história singular do menino nordestino que tudo superou e se tornou um cidadão do mundo através do trabalho e do estudo, se tornou um marco de nossas letras.

\section{CONCLUSÕES}

Para concluir, uma questão importante que não podemos perder de vista é o fato de que as duas obras literárias analisadas revelam aspectos educacionais do final do século XIX no Brasil, porém fazem uso da memória de maneiras diferentes. Em Minha vida de menina, Helena Morley escreve em tempo real, por se tratar do seu diário, utilizando-se, dessa maneira, de uma memória mais recente. Já em História da minha infância, Gilberto Amado já adulto escreve sobre sua infância.

Dessa maneira, é preciso problematizar a questão mnemônica segundo Jacques Le Goff (2003), quando afirma que a memória é a propriedade de conservar certas informações que remete-nos, primordialmente, a um conjunto de funções psíquicas, graças às quais o homem pode atualizar impressões ou informações passadas, ou que ele representa como passadas. Assim, “a memória, na qual cresce a história, que por sua vez a alimenta, procura salvar o passado para servir ao presente e ao futuro" (LE GOFF, 2003, p. 471). Ou seja, tanto a história quanto o ato mnemônico utilizam o comportamento narrativo para estabelecer a comunicação a outrem de uma informação, tendo em vista a ausência do acontecimento ou do objeto que constitui o seu motivo.

Por fim, asseveramos que analisar o emprego da Literatura para os estudos da história da educação da infância através de obras autobiográficas evidenciou a forte influência da História Cultural no campo historiográfico brasileiro. Bem como, a grande contribuição que essa vertente proporcionou as pesquisas nessa área, ampliando as possibilidades da utilização de diversas fontes, colaborando assim, para a construção de uma história mais desvinculada de documentos e fontes oficiais, como ocorria com o positivismo.

O exercício empreendido mostrou-se muito profícuo, especialmente pela riqueza de detalhes e pelo tipo de linguagem que as obras apresentam. Além de possibilitarem um novo olhar sobre velhas concepções.

\section{REFERÊNCIAS}

AMADO, Gilberto. História da minha infância. São Cristóvão, SE: Editora da UFS, 1999.

ARIĖS, Philippe. História da Criança e da Família. $2^{\mathrm{a}}$ ed. Rio de Janeiro: LTC, 1978.

BURKE, Peter. A Escola dos Annales (1929-1989): a revolução francesa da historiografia. São Paulo: Editora da Unesp, 1991.

CHARTIER, Roger. À beira da falésia: a história entre incertezas e inquietude. Porto Alegre: Editora da UFRGS, 2002. 
CHARTIER, Roger. Cultura escrita, literatura e história. Porto Alegre: Artes Médicas, 2001.

DAMAZIO, Reinaldo Luiz. 0 que é criança? São Paulo, Editora Brasiliense, 1995.

FERRO, Maria do Amparo Borges. Literatura escolar e história da educação: cotidiano, ideário e práticas pedagógicas. São Paulo: Faculdade de Educação da Universidade de São Paulo, 2000. Tese de doutoramento.

GOUVÊA, Maria Cristina Soares. A literatura como fonte para a história da infância: possibilidade e limites. In.: LOPES, Alberto; FARIA FILHO, Luciano Mendes de e FERNANDES, Rogério. Para a compreensão histórica da infância. Belo Horizonte: Autêntica, 2007.

KUHLMANN Jr, Moysés. Infância e educação infantil: uma abordagem histórica. Porto Alegre: Editora Mediação, 1998.

LAJOLO, Mariza; ZILBERMANN, Regina. A formação da leitura no Brasil. 2.ed. São Paulo: Ática, 1998.

LE GOFF, Jacques. História e Memória. 5 ed. Campinas, SP: Editora da UNICAMP, 2003.

MORLEY, Helena. Minha vida de menina. São Paulo: Companhia das Letras, 1998.

\footnotetext{
1. Pós-Doutoranda em Educação na Universidade Tiradentes (UNIT). Doutora em Educação pela Universidade Federal de Minas Gerais - UFMG (2013) com Estágio Sanduíche na Universidade de Lisboa (2012). Mestre em Educação (2009) e Graduada em Pedagogia (2005) pela Universidade Federal de Sergipe - UFS. Tem experiência na área de Educação, com ênfase em História da Educação, História da Infância, Educação Infantil, Ensino-Aprendizagem e Metodologia de Pesquisa. E-mail: solylima@hotmail.com

2. Mestre em Educação (2009) e Graduada em Pedagogia (2005) pela Universidade Federal de Sergipe. Professora da Universidade Tiradentes e Professora da Educação Infantil da EMEF Papa João Paulo II. E-mail: anne_cabral@hotmail.com
} 